\title{
The Effectiveness of Recommendation Engine Based on Consumer's Purchase Behaviour
}

\author{
D. Lakshmanan, S. Rabiyathul Basariya
}

\begin{abstract}
This study seeks to demonstrate the impact of content and advertising at constant time on consumer's obtaining behaviour. It wants several months to accumulate data and knowledge through kind, surveys, web site visits and walk-thorough investigations that unit the primary basis of this study work. This study distinguished that content is best on the shoppers WHO travel through the peripheral route and it'll leads the consumer's mind to finish switch. This study together found that content and advertising is much easier in low involvement category product where a straightforward promotional signal can lead the shoppers to buy for a product. This study together suggests to the marketers involved in mind of the new or unknown product, as content might have sturdy negative effects on consumers' internal worth reference and perceived quality. This work together highlights the importance of human action the advertising with utterly completely different promotional activities to reinforce the growth of sales of a product.
\end{abstract}

Keywords : publicity, Advertising, Purchase Behaviour, effectiveness, consumer.

\section{INTRODUCTION}

Industrial promoting ability is that the key of financial success. Finance, operations, accounting, and totally different functions won't terribly matter if there isn't snug demand for product to the company which is able to build a profit. today the marketers' unit of measurement terribly confounded to need up the fitting elevating procedure because of an assortment of item, swelled client's desire and speedy modern development. all through this circumstance, it's non heritablebrowse that a few advertisers don't have all the earmarks of being prudent to completely entirely unexpected limited time exercises and promoting where some others utilize these unwittingly. consequently it's an ideal opportunity to reconsider the genuine impacts of topic and publicizing on the shopper's psyche. topic has unendingly been a territory of the business advancing procedure and publicizing is that the premier well-preferred device acclimated arrive at clients. The allotment of the showcasing spending plan is by and by reallocating with limited time spending plan and publicizing that demonstrates its significance.

Presently a-days individuals unit of estimation mindful to

Revised Manuscript Received on September 22, 2019.

D. Lakshmanan, Research Supervisor, Department of Commerce and Business Administration, Bharath Institute of Higher Education and Research, Chennai.

Dr. S. Rabiyathul Basariya, Associate Professor, , Department of Commerce and Business Administration, Bharath Institute of Higher Education and Research, Chennai appear for the preeminent compelling one and that is the reason their shaky personality may initiate to new marks with clear information. all through this case a further motivator are generally superimposed to an item by absolutely entirely unexpected special exercises. some other time it's extraordinary that an item absence of Associate in Nursing fundamental preferred position are normally made it hard to make partner degree development which can be acclimated make individuals to attempt to the product. Propelled Chemical Industries (ACI) confined is that the preeminent extraordinary maker and dealer of homecare, toiletries, beautifying agents and pharmaceutical item for abuse and sexual practice individuals the whole way across land. The Vanish purging operator might be a house synthetic of ACI Formulation confined. This desk work began with it as an example in affecting the business volume through topic and publicizing. This examination work can change unmistakable the numerous extent of infiltration through topic and publicizing. By perceptive the investigation result there'll be partner degree improved comprehension of why and what instruments or administrations need to offer and furthermore the way can set up the main situation in such forceful market. The point of the paper is all things considered, as a dealer, what impacts topic and promoting awfully wear purchaser's purchasing conduct by dissecting savvy and hypothetical confirmations. anyway the outcomes got from the investigation work is also self speakable. the singularity can likewise be even from absolutely entirely unexpected perspectives on determined outcomes. Since ten speculations were made a decision on absolutely very surprising qualities, the outcomes were some way or another completely entirely unexpected from the up to as of now bolstered outcomes. There together discovered some conflicting outcomes from the quality ones. as partner degree model, amount blessing as a customary conviction assumed to be a solid advancing apparatus for expanding piece of the overall industry however here some exemption were found.

\section{INDUSTRIAL PROMOTING}

In late decades totally various scientists and professionals stresses on maker's publicizing and advancement exercises which will build piece of the pie. Anselmi (2000) the relative piece of the overall industry is moreover affected by producer's publicizing and advancement assignment choice. He all things considered superimposed that publicizing builds up the producer's association with the merchants and assignment to advancement are typically expanded regarding separate relationship among 
them. Complete with low relative piece of the pie may encounter bigger likelihood for publicizing in relative trade and weight for advancement in discrete trade.

Teng (2009) intends to demonstrate the impressive impacts of the value limits. He clarified that value limits may alteration buyers' frames of mind and gain goals in regards to a specific complete by moving it from shoppers' hold set to thought set. Here it's normally superimposed that the benefactor doesn't give off an impression of being separated from everyone else delicate to esteem yet all in all to the organizations' promoting endeavors (Huang et al., 2012).

Jones (2003) contended here as, by and large, expanded promoting consumption creates alone at minimal low normal volume of extra deals which can some of the time be gainful. He grouped the promoting impacts in a matter of seconds, medium, and part of the arrangement. The underlying outcome are generally positive and a past condition for the more drawn out impacts. The medium-term contains a positive impact of the brand's very own promoting extra as negative impact for focused brands.

Once more, per Sandra et al (2008) everybody got the chance to see the job that promoting is interesting in stylish life. Mentally it shapes the frames of mind of the general public and consequently the individual impacting their conduct. It all things considered gives huge measure of data to customer to shape a range and reach an inference. Hyun et al (2011) all in all elucidates that publicizing incited passionate reactions totally impact supporters' apparent worth. He demonstrates four elements of publicizing (pertinent news, incitement, compassion, and commonality) that seriously affect incurring supporter's passionate reactions. Adjacent to of these constructive outcomes, the advertisers even should utilize alert with respect to their prudent employments. what is more Dens (2010) looks at a couple of types of publicizing systems like enlightening versus positive enthusiastic. He finds that educational interests contrasted with enthusiastic interests diminish the aftereffects of parent total quality and match. It got to on the whole consider the geological area of the supporter which can assumes a noteworthy job with respect to the reaction of promoting and message. Relating this issue, unpracticed (1995) looks at the reactions of African-American and yank clients to four types of retail deals advancement coupons, item shows, highlight ads, and worth limits. Results found imperative varieties between these a couple of types of customer alone in their utilization of pennies off coupons.

\section{FINDINGS}

The findings encourage rethinking the assumption that advertising has such a strong influence on shopper behaviour. Advertising isn't primarily powerful enough to completely differentiate brands albeit it's been found to contribute to different necessary aspects, like providing content Associate in Nursing protecting associate degree already established complete. Therefore, form of organizations sq. measures moving their funds away from advertising to message, PR and selling. The findings might build a mental confusion to many marketers of the thanks to assign their budgets; so, this can be often an issue that needs to be addressed. If the assumption can be accepted that advertising may be a higher tool for establishing and reinforcing the patron purchase behaviour than message, the answer for companies would be simple they'd merely use advertising and ignore the rest of the promotional mix.

However, all the marketers need to suppose the thanks to use these every successfully for spanking new or unknown product. the patron might not be intended to shop for product that unit of measurement on promotion, as a results of the patron doesn't want his image to be joined to being a "cheap shopper". This result's conjointly applied to every unknown and well-known product. yet again it ought to seem to shopper that inferiority ad and lower value can indicate inferior quality, as a results of customer's link ad and price to quality. This facet is most significant for spanking new or unknown product, as a results of customers hasn't any previous experience with the merchandise. However, well-known product inside the short term won't be affected identical technique as new or unknown product, because, customers apprehend the quality of the merchandise, then it'll not have a large impact of the perceived product quality. As seen on Shaping to Repeat Purchase Behaviour, if a replacement or unknown product is being promoted, it'll begin with lowering the value. As a result, the inside reference price is down. Moreover, as a results of the value is down, the quality perception to the patron is also down too. identical are true for a widely known product; however, the tactic of building negative impacts might longer, as a results of the merchandise already has designed up some positive experiences to the purchasers. The supported results collectively dissent from previous findings and ancient beliefs. as associate degree example here this analysis work hypothesized that quantity discounts is good for increasing market share but once inserting mathematics values it had been rejected that suggests amount gifts, incentives etc isn't endlessly useful for all kind of things or promoting policies.

\section{RESULT AND CONCLUSION}

The paper has incontestable victimization some advanced questionnaires Associate in Nursingd hypotheses that the advertising has associate degree ambiguous impact on shopper behaviour. Since seven out of ten observations everywhere with the positive results that sales volume is in charge of increasing market share in conjunction with profit maximization. The findings of this paper would supply a serious facilitate to the manufacturer regarding their competitive promoting strategy. Here throughout this paper the authors used a handsome amount of sample populations bearing utterly completely different demographic and psychological views. The limitation of this paper is that this work principally targeted on the short term effects of message and advertising on the consumer's behaviour. simply just in case of further future analysis work, the potential analysis workers need to contemplate further samples data and collectively judged on contingency basis since analysis philosophy further as a result of it relevant tools unit of measurement dynamic in nature. However, it's of necessary importance to understand the long-standing time effects of message on the consumer's purchase behaviour collectively. 
what is more the authors unit of measurement hopeful that the outburst of this work can facilitate to maximise the provision chain gain by deed the competitive ways for any specific manufacturing firm.

\section{REFERENCES}

1) “Aaker, Myers \&Batra : Advertising Management, Prentice Hall,1992

2) Wells, Moriarity\& Burnett : Advertising Principles \& practices, Prentice Hall,2005

3) Kleppner's Advertising Procedure: W.Ronald Lane, kaneWhitehill king and J. Thomas Russell, Pearson Education, 2010

4) Dr. S. Rabiyathul Basariya, and Dr. NabazNawzad Abdullah, Dec 2018. “A STUDY ON CUSTOMER'S SATISFACTION TOWARDS E-BANKING”, International Research Journal of Management and Commerce, Volume 5, Issue 12

5) George E.Belch\& Michael A. Balch: Advertising and Promotion, TMH,2014.

6) S.H.H Kazmi and SatishK.Batra : Advertising and sales promotion, Excel books, 2009

7) D. Lakshmanan and Rabiyathul Basariya, ROLE AND THE VALUE OF CREATIVITY IN THE EFFECTIVENESS OF ADVERTISING "Understanding the Value of Creativity in Advertising" International Journal of Research in Management ISSN 2249-5908 ,Issue 7, Vol. 3 (May 2017)

8) Essential Marketing and Advertising Dictionary (2009) by Jerry Rosenberg ISBN: 9781572487031 Sphinx Dictionaries. 